\title{
RESUMO
}

ISSN Digital: 2316-3828

ISSN Impresso: 2316-333X

DOI: 10.17564/2316-3828.2020v10n2p110-123
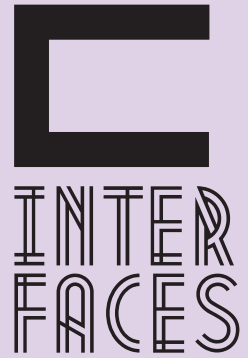

CIENTÍFICAS

\section{DIÁRIOS DE AULA VIRTUAL E A CAUTO] FORMAÇÃO NA PESQUISA EM REDES COLABORATIVAS}

VIRTUAL CLASSES DIARIES AND (SELF) TRAINING IN THE RESEARCH IN COLLABORATIVE NETWORKS

\section{CLASES VIRTUALES Y (AUTOJ INVESTIGACIÓN} DE FORMACIÓN EN REDES COLABORATIVAS
Ana Lúcia Gomes da Silva ${ }^{1}$

Laís Oliveira Abreu²

Vaneza Oliveira de Souza ${ }^{3}$
0 presente artigo objetiva apresentar a experiência do uso do diário de aula virtual no componente curricular Pesquisa Aplicada à Educação II (PAE II) em um Programa de Pós-Graduação da Universidade do Estado da Bahia (UNEB). A cartografia como método utilizado se constitui de pistas a partir de narrativas de discentes e docentes e da revisão bibliográfica embasada em Santos e Weber (2018); Ribeiro e Barbosa (2018); Monteiro e Mendes (2018) e Marcuschi (2001). Evidencia-se por meio das pistas o potencial do diário de aula virtual como dispositivo (auto)formativo de educadores/ as pesquisadores/as. Tendo o ethos da confiança como móvel da rede rizomática, os diários vivificam experiências que articulam formação, heteroformação e conformação por meio do compartilhamento de sentidos, de modo horizontalizado, que reverberam no (e para além) do processo de ensino e de aprendizagem. Os dados emergentes das narrativas apontam que os ambientes virtuais de aprendizagem podem ser concebidos como expansões do espaço da sala de aula presencial que possibilitam a ampliação do tempo-espaço formativo e a horizontalização dos processos de ensinar e aprender, bem como potencializa a autoria e inventividade.

\section{PALAVRAS-CHAVE}

Diário de Aula Virtual. Formação. Rede Colaborativa; rizoma; plataforma Trello. 


\section{ABSTRACT}

The current article aims to present the experience of using the virtual classroom diary in the curricular component Research Applied to Education II - PAE II in a Postgraduate Program at the State University of Bahia - UNEB. Cartography as a method used consists of clues based on the narratives of students and teachers and the bibliographic review based on researchers such as Santos and Weber (2018); Ribeiro and Barbosa (2018); Monteiro and Mendes (2018) and Marcuschi (2001). The potential of the virtual classroom diary as a (self) formative device for educators/researchers is shown through the clues. With the ethos of trust as the motive of the rhizomatic network, the diaries vivify experiences that articulate formation, heteroformation and conformation through the sharing of meanings, in a horizontal way, which reverberate in (and beyond) the teaching and learning processes. We realized, therefore, that the virtual learning environments can be conceived as extensions of the classroom space that allow the expansions of the formative time-space and the horizontalization of the teaching and learning processes, as well as enhances authorship and inventiveness.

\section{KEYWORDS}

virtual class diary; formation; collaborative network; rhizome; Trello platform.

\section{RESUMEN}

Este artículo tiene como objetivo presentar la experiencia de usar el diario virtual del aula en el componente curricular Investigación aplicada a la educación II - PAE II en un programa de posgrado en la Universidad Estatal de Bahía - UNEB. La cartografía como método utilizado consiste en pistas basadas en las narraciones de estudiantes y profesores y la revisión bibliográfica basada en Santos y Weber (2018); Ribeiro y Barbosa (2018); Monteiro y Mendes (2018) y Marcuschi (2001). El potencial del diario virtual del aula como un dispositivo (auto) formativo para educadores/investigadores se muestra a través de las pistas. Con el espíritu de confianza como el motivo de la red rizomática, los diarios vivifican experiencias que articulan la formación, la heteroformación y la conformación a través del intercambio de significados, de manera horizontal, que repercuten (y más allá) en el proceso de enseñanza y aprendizaje. Los datos que surgen de las narraciones señalan que los entornos virtuales de aprendizaje pueden concebirse como expansiones del espacio del aula que permiten la expansión del espacio-tiempo formativo y la horizontalidad de los procesos de enseñanza y aprendizaje, así como mejorar la autoría y la inventiva. 


\section{PALABRAS CLAVE}

diario virtual del aula; entrenamiento; red colaborativa; rizoma; Plataforma Trello.

\section{PISTA INTRODUTÓRIA}

Este artigo tem como objetivo central apresentar a experiência do uso do diário de aula virtual no componente curricular Pesquisa Aplicada à Educação II (PAE II), no semestre 2019.1, no Programa de Pós-Graduação em Educação e Diversidade da Universidade do Estado da Bahia (UNEB).

Orientadas pela perspectiva da composição, neste trabalho que se (des)orienta por meio de pistas, propusemo-nos analisar as interações assíncronas realizadas na plataforma virtual Trello ${ }^{4}$. Estas concebidas como expansão dos tempos formativos do componente curricular PAE II.

Buscamos exercitar "[...] o modo como pensamos, educamos, e estamos sendo; o modo que produzimos e lemos; visando transformar, não copiar modelo" (KHOAN, 2002, p. 124). Este exercício foi proposto por meio do diário de aula on-line, dispositivo de pesquisa e ao mesmo tempo de formação para as educadoras-pesquisadoras autoras e coautoras da experiência aqui gestada.

“Escape às amarras institucionais" (MONTEIRO; MENDES 2018, p. 17), a plataforma virtual Trello foi utilizada como extensão-expansão da sala de aula - de modo colaborativo e rizomático - por objetivar a circulação das aprendizagens como centralidade entre estudantes e docentes a fim de mobilizar temas e conceitos estudados e sobre eles refletir, construindo a formação do/a professor/a-pesquisador/a.

Pautadas na perspectiva do hipertexto como "uma inter-relação de vários textos ou narrativas e da possibilidade de dialogar com a polifonia em rede” (SILVA, 2010, p. 41) articulada à concepção deleuziana do rizoma, trazemos neste texto as vozes de alunas e docentes que vivenciaram a experiência com o uso dos diários de aula virtual por meio da plataforma Trello. Nesta, os diários ganharam publicidade e puderam ser compartilhados de forma síncrona e assíncrona, sobrepondo ao limite comunicacional do suporte físico.

Entendemos que esse texto que se estrutura em pistas cartográficas contribui para suscitar possibilidades pedagógicas (auto)formativas outras, maturadas com as experiências que vão acontecendo nas vivências das relações processuais que constroem a (auto)formação do/a professor/a pesquisador/a. Sempre em devir, este compreendido como produção, possiblidades de criação, meio de estar atento/a ao processo, seus movimentos e efeitos de sentidos. É um mapa aberto (DELEUZE; GUATTARI, 2011).

4 Ferramenta utilizada para organizar projetos pessoais e corporativos, que funciona como um painel de gerenciamento e permite personalizar os fluxos de trabalho e estudo para uso pessoal ou coletivo. Para saber mais acesse: https://trello. com/b/w2PvS6kZ/di\%C3\%A1rios-de-aula-pesquisa-pae-ii. Acesso em: 09 de agosto, 2020. 


\section{PISTA DOIS - MÉTODO}

Para se pensar em outros modos de construção de aprendizagens colaborativas é preciso pensar também, de outro modo, os espaços formativos e as relações de aprendizagens. Alinhada a esta perspectiva, o método cartográfico é o que nos possibilita abarcar a experiência de formação como uma composição, com variações e improvisos, conforme propõem Monteiro e Mendes (2018). Um processo interventivo tecido com e partir de uma coletividade envolvida, levando em conta experiências individuais que construíram uma experiência coletiva.

O método inspirado na filosofia da diferença de Gilles Deleuze e Félix Guattari não é linear, parte de pistas vívidas que são constituídas e construídas no processo; não busca representar uma realidade, mas nela intervir (BARROS; KASTRUP, 2015). Nessa perspectiva, a cartografia se constitui do corpus de algumas das narrativas selecionadas para cartografar a experiência de discentes e docentes no âmbito do Programa de Pós-Graduação em Educação e Diversidade da UNEB e da revisão bibliográfica a partir dos estudos de Santos e Weber (2018), Monteiro e Mendes (2018), Ribeiro e Barbosa (2018), dentre outros/as.

Os conceitos da cartografia tomados neste texto para apresentar as narrativas são: rizoma, plano comum, processualidade e experiência ancorada no real. Além disso, e tão relevante quanto os conceitos da cartografia, destacamos que o nosso tecer funde sujeito e objeto.

Segundo Romagnoli (2009, p. 171) “a cartografia se contrapõe às pesquisas cientificistas tradicionais, objetivando romper com as dicotomias teoria-prática, sujeito-objeto, articulando pesquisador e campo de pesquisa”. Aqui são as próprias autoras que cartografam e são cartografadas pela experiência de pesquisa-formação construída, conforme as pistas a seguir.

\section{PISTA TRÊS - RESULTADOS E DISCUSSÃO - NARRATIVASE DESLOCAMENTOS TERRITORIAIS}

A disciplina PAE II é um componente curricular obrigatório no Programa de Pós-graduação já citado que propõe espaço de reflexão sobre como construir pesquisas em educação a partir da dinamicidade e pluralidade inerentes aos fenômenos sociais. Nesse movimento, as propostas apresentadas no componente tomam como ponto de partida e chegada os processos formativos e autoformativos do/a professor/a pesquisador/a ao (des)aprender a construir possíveis caminhos de pesquisa, considerando a diversidade dos sujeitos, dos territórios, de métodos e de todos os processos teórico-metodológicos que os envolve.

Apesar de estarmos posicionadas em lugares distintos (professoras - alunas), a pedagogia vivenciada a partir das trocas síncronas (em sala de aula) e assíncronas (plataforma virtual Trello) de caráter colaborativo, desconstrói a ideia hierárquica de superioridade, distanciamento e apartamento entre docentes e discentes. A construção é horizontalizada, não linear, por isso da ordem do rizoma (da multiplicidade), não remetendo às vontades individuais de um sujeito, mas às variadas linhas 
que se deslocam e se conectam a outras dimensões para além da posição (raiz fixa) de uma árvore (DELEUZE; GUATTARI, 2011).

Como os diários podem constituir meios de (auto)formação? Como se dá a transposição da escrita da esfera privada para o coletivo? Como se processa a escrita no coletivo? Valemo-nos de Santos e Weber (2018) para entender os movimentos de diarização da perspectiva acadêmica, sobretudo na formação para/na pesquisa. Ao longo das nossas narrativas cartográficas vamos buscando compreender esses processos.

\section{A EXPERIÊNCIA DO USO DO DIÁRIO DE AULA VIRTUAL NO COMPONENTE CURRICULAR PES- QUISA APLICADA À EDUCAÇÃO II}

No início do semestre 2019.1 ao ser apresentado o Plano de ensino e de aprendizagem e o cronograma de aulas da disciplina PAE II para a turma, as docentes provocaram estranhamento nas 13 mulheres mestrandas. Estranhamento decorrente da ousadia das inúmeras proposições.

Dentre os novos procedimentos metodológicos propostos para o componente estavam justamente os diários de aula. 0 cronograma das aulas, detalhado em 10 páginas, trazia estrutura das aulas, critérios de avaliação e logo abaixo dos nove critérios avaliativos constava a seguinte observação: Todas as estudantes elaborarão/entregarão ao final da Unidade I o diário das aulas com a auto avaliação pessoal e do grupo seguindo os critérios registrados no plano do referido componente curricular.

Imersas nos modelos formativos experienciados na graduação e cursos de especialização, assim como em nossas práticas profissionais, considerando que nove das treze alunas são professoras da educação básica, não estávamos familiarizadas com a proposta, pois até então não era habitual para a grande maioria o uso do diário.

Nesse momento inicial fomos interpeladas para sairmos da zona de conforto onde nos sentíamos seguras para pensar a possibilidade de escrever sobre nossas trajetórias nas aulas, sobre nossos saberes e não saberes, um movimento de relato de si (BUTTLER, 2015) que provocava medo, tanto pelo processo de escrita, que propunha o entrelaçamento teórico-reflexivo em um componente denso, como pela possibilidade de tornar pública a escrita, pois por meio da plataforma virtual os diários ganhariam contornos de texto público.

Segundo Santos e Weber (2018, p. 50), uma das principais caraterísticas do diário é o "registro dos acontecimentos do dia a dia, ou seja, do cotidiano vivido e refletido pelo autor". Por meio dos diários fomos desafiadas a narrar o cotidiano das aulas, partindo de uma escrita reflexiva que parece lançar luz ou tornar consciente o percurso da aprendizagem, o que vai muito além dos modos de ensinar e aprender tradicionalmente validados pela academia. Estávamos diante de outras formas de construção de aprendizagens, "centradas nos sujeitos que aprendem, no aprender e não no ensinar" (MONTEIRO; MENDES 2018, p. 16), na formação pensada como com-posição em que se criam possibilidades de deslocamentos.

Como colocam Ribeiro e Barbosa (2018, p. 76), a utilização do diário possibilita “[...] o exercício da autoria e da tessitura de olhares plurais no/sobre/com o processo de registrar suas impres- 
sões, angústias, desejos, aprendizagens e questionamentos, refletindo sobre temas diversos que perpassam o currículo na interação dentrofora da universidade". A cada ida e vinda aos registros, o texto aprofunda-se. E isso só é possível porque quem diariza se permite em algum momento não mais temer o exercício de dizer o que vem da subjetividade das aprendizagens experienciadas. Se não nos toca profundamente, se não nos desloca, não tem diário. 0 diário faz nó, nos revira, conecta e desconecta. É rizoma.

Atravessadas por múltiplas emoções percebíamos ao escrevermos os diários os saberes construídos, as desconstruções vivenciadas, nos avaliávamos, avaliávamos a turma, as professoras e suas práticas pedagógicas - intencionais e marcadas por um movimento de oportunizar as aprendizagens e tensionamentos no/do coletivo. Começamos a perceber a potência de nossas subjetividades na construção de transformações educidadãs, além-muros da academia.

Segundo Santos e Weber (2018, p. 1) os diários on-line "[...] incorporam os aspectos comunicacionais e pedagógicos, bem como a emergência de um grupo-sujeito que aprende enquanto ensina e pesquisa e pesquisa e ensina enquanto aprende”. Nesse sentido, a escrita do diário ou prática do diarismo configurou-se como dispositivo que permitiu a reflexão sobre o vivido nas aulas de PAE II a partir das experiências tecidas nas rodas de leituras, discussões dos temas, escritas diversas e vivências no campo de pesquisa, bem como o compartilhamento de sentidos gestados tanto nos diálogos das professoras-pesquisadoras consigo mesmas, como nas situações de interação com as colegas e docentes, com as teorias e seus autores/as.

Trata-se de uma forma mais abrangente de conceber os processos formativos em que se admite que "não existe aprendizagem desvinculada da vida, das experiências aprendentes dos sujeitos sociais. A aprendizagem se realiza no ato da interação, no processo de conhecer a si enquanto se conhece o mundo" (RIBEIRO; BARBOSA, 2018, p. 78). A escrita refletida que dá corpo e sentido aos diários é uma forma de sistematização da experiência formativa e (auto)formativa, vivenciada em colaboração, que ganha visibilidade nas ambiências de compartilhamento das narrativas.

A emergência de novos espaços de compartilhamento a partir da ampliação de práticas educativas on-line, dos ambientes virtuais de aprendizagem e do acesso a dispositivos digitais, alargou as possibilidades de interações formativas ao romper restrições espaço-temporais. Além disso, a mediação por tecnologias em rede no ciberespaço marcou a transição dos diários materiais e de acesso restrito para os diários on-line, que podem ser acessados e comentados, potencializando a interação com/entre autores e leitores/as.

No espaço virtual os diários produzidos ganharam efetivamente a configuração de hipertexto com caraterísticas de polifonia, intertextualidade, "um processo de escritura/leitura eletrônica multilinearizado, multisequencial e indeterminado, realizado em um novo espaço de escrita” (MARCUSCHI, 2001, p. 86), mais coletivo e colaborativo. Portanto, a autoria e coautoria se fizeram efetivas e afetivas nesta experiência (auto)formativa. 


\section{DIÁRIOS DE ITINERÂNCIA - A CONSTRUÇÃO DE UM PLANO COMUM HETEROGÊNEO}

No ambiente virtual ampliaram-se as possibilidades de interatividade e diálogo e os diários constituíram-se como dispositivos de "mediação de processos reflexivos (na ação e sobre a ação) em cenário de ensino e pesquisa-formação” (SANTOS; WEBER, 2018), em que todas as estudantes posicionaram-se como sujeitas que ensinam e aprendem em rede colaborativa.

Nesse sentido, podemos caracterizar como atos de diário ou até mesmo de diário de itinerância na perspectiva de Barbier (2002) os movimentos de relatoria de cada roda de leitura realizada no decorrer do semestre 2019.1. As rodas se desenvolviam a partir de leitura individual de textos previamente indicados que posteriormente eram debatidos no coletivo por meio da mediação de duas discentes.

A mediação tinha como critério a rotatividade, assim como as relatorias. Apesar de as rodas serem atividades de cunho presencial, algumas delas aconteceram on-line, diretamente na plataforma Trello. A relatoria era rascunhada em aula, depois elaborada e posteriormente disponibilizada no Trello para que todas pudessem comentar e dar as suas contribuições.

Barbier (2007, p. 138-142), caracterizando os diários de itinerância, afirma serem meios que refletem mais os sujeitos e suas contradições, muito além de um mero caminho retilíneo. A escrita do diário de itinerância pode ser mapeada em três fases: 1 - diário rascunho; 2 - diário elaborado e 3 - diário comentado. A primeira reflete um momento mais individual, seria a escrita de tudo que vier a mente sobre a situação vivenciada. A segunda é uma (des)organização do rascunho, articulada a outras teorizações, criação mais elaborada para ser compartilhada com o coletivo. A terceira é a fase da partilha, para a construção do diário de itinerância coletivo.

Ousamos afirmar que realizamos em PAE II um diário de itinerância coletivo por meio da relatoria das rodas de leitura: 1 - A roda de leitura era relatada em aula por duas colegas, que captavam o que acontecia ao longo das discussões (rascunho); 2 - após a roda, as escritas da dupla relatora eram articuladas e enriquecidas com outros elementos poéticos, científicos, filosóficos (elaborado) e 3 após essa revisão o diário era disponibilizado para o coletivo na plataforma Trello, e também lido e dialogado em sala de aula (comentado).

Percebemos que a diarização acontecia em caráter processual e rizomático: em momentos de escritas solitárias, em outros momentos feita a várias mãos, num movimento de ziguezague nunca acabado. Para Marcuschi (2001, p. 87), esse tipo de narrativa polifônica, diarizada, é construída em “forma de uma estrutura em nós e ligações”, daí seu caráter rizomático.

Na perspectiva de Deleuze e Guattari (2011), o rizoma pode se desconectar e ser conectado a qualquer ponto a qualquer momento, as ligações são constituídas sempre em devir, atando e desatando nós, tal como os diários on-line e as interações que ele gera. Os pontos de análise que se intercruzam a partir de cada escrevente foram percebidos como exercícios de autoria e reflexão dos temas estudados.

Observamos pela nossa experiência que as memórias diarizadas em rede diluem as subjetividades, mas preservam a individualidade de cada sujeito. Os gestos de autoria ao mesmo tempo são gestos de coautoria, evidenciando os traçados de um coletivo que se constitui no dinamismo entre 
singularidades e pluralidades, se horizontalizam na humanidade de cada uma e transversalizam em suas multiplicidades. É assim que se constitui o plano comum heterogêneo. Destacamos a potência do diário de aula virtual na construção deste plano comum heterogêneo por meio de experiências (auto)formativas de caráter colaborativo.

\title{
6 A CONSTRUÇ̄̃̃O DO ETHOS DA CONFIANÇA - EXPERIÊNCIA ANCORADA NO REAL
}

\begin{abstract}
O movimento de escrever e retornar tempos depois às páginas acaba nos dando um panorama diferenciado sobre a sucessão dos dias: neste vai e vem de escrita e leitura do diário é possível ver poesia naquilo que está impregnado pela cotidianidade da vida. É ter o que dizer sobre ela, mesmo quando se apresenta de forma aparentemente igual ao que é sempre. (NUNES, 2015, p. 3.349).
\end{abstract}

A partir desta epígrafe trazida para escrevermos esta pista percebemos que o exercício de ver poesia nos escritos do cotidiano não se dá da noite para o dia, é uma construção processual que acontece nos movimentos não lineares da diarização. Daí o porquê de arriscarmos afirmar que o ethos da confiança é o móvel da rede rizomática que acontece no processo de diarizar a experiência. Mas quando e como se dá a constituição do ethos da confiança?

Segundo Sade, Ferraz e Rocha (2015) a produção da confiança precisa ser cultivada. Não basta dizer que é preciso confiar. 0 processo demanda tempo e se fortalece no coletivo. Se dá pelo cultivo do afeto. O ethos da confiança é meio e fim, "meio porque responde pelo engajamento com base em uma experiência compartilhada, e fim porque esse engajamento ganha sentido ampliando a potência de criação coletiva de territórios existenciais" (SADE; FERRAZ; ROCHA, 2015, p. 89).

Isso pode ser visualizado no seguinte trecho do diário da mestranda produzido na disciplina de PAE II:

[...] o que tem nos movido, portanto, são as dúvidas. Movimentamo-nos juntas numa descoberta que se enriquece porque é tecida na coletividade, que se traduz em desejo de construir uma pesquisa-intervenção pautada num ethos que também vem sendo maturado nas vivências, na troca de experiências, em rede... (LAÍS, 2019).

Como se vê, mesmo vivenciando um período marcado por dúvidas, a experiência e o ethos foram amadurecidos no processo do fazer com. Destacamos o con de confiar, o com de compartilhar e o co de coletivo - nessa rede de composição e criação (SADE; FERRAZ; ROCHA, 2015). Isso nos ajuda a caracterizar as tessituras diarizadas como meio de produção coletiva do conhecimento.

Quando os diários foram partilhados no Trello percebemos as nossas singularidades, os desafios que nos humanizam e a força das nossas narrativas. Percebemos o plano comum heterogêneo que foi constituído - mulheres construindo experiências de engajamento - e o aumento da potência de agir a partir da abertura desta rede fiada com mulheres. Rede de afeto e confiança. 
A confiança [...] ajuda-nos a discutir o aspecto ético da cartografia em sua conexão com o aspecto metodológico. 0 ethos da confiança tem o sentido de abertura ao plano da experiência e de aumento da potência de agir. [...] Em vez de um regime de suspeita em relação à experiência, no qual toda dimensão de vínculo é tratada sob a égide do controle e do juízo, a cartografia aposta na riqueza deste plano. Conta com a sua potência de criação, abrindo-se para ser articulada por ele. Eis o que encontramos na palavra confiança - con fiar - fiar com, tecer com, composição e criação com o outro/outrem. (SADE; FERRAZ; ROCHA, 2013, p. 283).

Como já dito, a construção da confiança não se deu de modo imediato. Foi alinhavada na processualidade $^{5}$ dos acontecimentos. Foi cultivada na perspectiva da centralidade ética da cartografia, já que o método cartográfico implica dar e pôr atenção ao que surge em campo, nos encontros e habitação do território. Como afirmam Prado Filho e Tetti (2013), entre jogos e movimentos, relações, enfrentamentos entre forças, lutas, versões de verdade, modos de nos subjetivar, estetizar pesquisa e escrita, literaturizando o conhecimento científico, tecendo pesquisa e vida.

Na cartografia o método não é tomado como proposição de regras, procedimentos ou protocolos de pesquisa lineares, áridos, mas sim, como estratégia de análise crítica e ação política, forjados pelos olhares das pesquisadoras/es ao acompanhar e descrever relações, trajetórias, num constante ir e vir que se entrecruzam. Essa construção cultivada para constituição da rede de afeto e compartilhamento de experiências também aparece nas narrativas da mestranda Vaneza (2019):

Apesar da pressão que senti no início, da densidade do componente e das fragilidades acumuladas no que se refere à metodologia e métodos de pesquisa, vivenciei em PAE I e II, assim como as companheiras de turma (creio), o que é aprender com, aprender de forma colaborativa, dialogada e generosa, e essa vivência permanecerá em nós, nos atravessando e marcando nossas trajetórias como pesquisadoras, professoras e demais profissionais.

A mestranda também destaca que o processo foi construído com - colaborativamente. A potência das narrativas é evidenciada à medida que traz o percurso não linear, as linhas duras que atravessavam cada uma, bem como o processo de construção das aprendizagens. Sem a confiança não sairíamos das nossas zonas de conforto. Se as professoras não dissessem: Vamos fazer! Não teríamos como construir confiança. Elas confiavam e nós precisávamos confiar juntas. Ao ler e reler, ir e voltar nas nossas escritas, os encantamentos foram aflorando: era a confiança se manifestando para nós e em nós.

Nesse momento de afloramento da confiança desenvolvíamos a capacidade de perceber a potência formativa e autoformativa do diário. Trazemos trechos da narrativa de Vaneza mais uma vez para mostrar esse movimento de percepção de potências que se dá no plano da experiência (PASSOS; BARROS, 2015).

5 A processualidade neste estudo que toma o método cartográfico na sua inspiração metodológica e epistêmico-política, diz respeito aos seus avanços, pausas e paradas, ao longo do processo de pesquisa em letras e linhas, na escrita, em nós e conexões que emergem. Os aprendizados são permanentes e permite a autoconstrução e a construção a todo o tempo, já que a processualidade demanda a produção coletiva do conhecimento (BARROS; KASTRUP, 2015). 
A escrita dos diários, compartilhados dentro do ambiente virtual de aprendizagem (Trello), nos coloca diante de uma nova vivência, de novas tessituras de conhecimento em rede, como afirmam Santos e Caputo (2018). Demorou um pouco para compreender seu caráter como dispositivo de formação e autoformação, que possibilita o compartilhamento de sentidos por meio dos registros e escrita refletida a partir de nossas ações, reações, sentimentos, impressões e desassossegos. Como diria a professora, as vendas demoram a cair, mas caem, para cada uma a seu tempo e a tempo. Por isso, ao retomar este diário, relê-lo e reelaborá-lo com outro olhar, observo também um amadurecimento sobre a forma como percebo este dispositivo e sua função potente na pesquisa-formação, um espaço-tempo onde nossos registros comunicam sentidos singulares e subjetivos das experiências vividas no coletivo nas aulas de PAE II. (VANEZA, 2019).

Observamos na narrativa que o plano da experiência, também chamado de plano de produção ou de coemergência - que se dá no processo, é quem aponta as pistas dos efeitos desse processo da produção da escrita sobre ela. 0 caminho metodológico é o "do saber na experiência à experiência do saber" (PASSOS; BARROS, 2015, p. 17-18).

Neste relato observamos um duplo movimento de deslocamento. 0 primeiro emerge da percepção da potência do diário no seu processo autoformativo como dispositivo que mobiliza a escrita refletida e a compreensão do processo de ensinar e aprender como um acontecer provisório, em devir. 0 segundo fica evidenciado pela maneira como a narrativa revela a sua relação com o diário.

As idas e vindas sobre o texto escrito configuram-se como movimentos importantes na prática da diarização, pois, como vimos em Nunes (2015, p. 3.349), "o movimento de escrever e retornar tempos depois às páginas acaba nos dando um panorama diferenciado sobre a sucessão dos dias" tensionando-nos a (re)dimensionar o sentido da experiência vivida e refletida e a (re)pensar pequenos acontecimentos que nos tocam ou provocam mudanças.

Esse movimento faz parte do princípio da construção cartográfica, por isso escolhemos este método para construção desta escrita. Segundo Deleuze e Guattari (1995, p. 21), "a cartografia surge como um princípio do rizoma que atesta, no pensamento sua força performática, sua pragmática, um princípio inteiramente voltado para uma experiência ancorada no real". Percebemos nessa perspectiva ancorada no real o regime afetivo de articulação e as transformações dela decorrentes. Transformação, formação e autoformação das pesquisadoras e articulação do coletivo formado no processo interventivo (BARROS; KASTRUP, 2015).

Constatamos dessa experiência, ancorada no real os diários on-line, como hipertextos onde a escrita forma uma tessitura não linear e descontínua (portanto, rizomática) onde as autoras revelaram-se investigadoras de si e de sua prática em contextos plurais de ensino-pesquisa-aprendizagens e construíram novos olhares para seu processo formativo por meio de uma rede de colaboração e interatividade. Olhares caleidoscópicosque possibilitam perceber o dinamismo da realidade, suas brechas e suas frinchas.

A partir da construção do ethos da confiança as mestrandas puderam compartilhar no ambiente virtual a escrita refletida a partir da experiência diarizada que oportunizou a percepção do diário 
como dispositivo que permite ver poesia no movimento (auto)formativo em rede - com suas nuances de dúvidas, descobertas, (des)construção, deslocamentos, (re)elaboração de sentidos sobre pesquisa, formação e autoformação.

\section{PISTA QUATRO - CONCLUSÕES PROVISÓRIAS}

Por meio das pistas que articulam narrativas e teoria entendemos que a nossa experiência em PAE II constituída na interatividade híbrida e horizontal por meio das aulas presencias e da plataforma virtual Trello constitui meio de composição que contribui para “[...] pensar em construir outras subjetividades docentes, criando práticas que superem as tentativas de fazer com que os alunos sejam rendidos a movimentos de assimilação de um conjunto de conteúdos" (MONTEIRO; MENDES, 2018, p. 17).

Deste modo, nossa concepção de formação docente implica experiência, sensibilidade, ação social, caracterizando uma intervenção que toma a realidade em seu processo multidimensional como ponto de partida-chegada de modo a nos (re)inventarmos como docentes que ensinam e pesquisam e pesquisam e ensinam, objetivando tecer novos modos de realizar pesquisa em educação, cuja produção da experiência é considerada como produção do conhecimento científico.

Experiências com práticas educativas on-line tornam-se aliadas ao romper restrições espaço-temporais, potencializando o diálogo com/entre textos, autores/as e leitores/as, de modo não hierarquizado. De igual modo, tomamos a experiência aqui narrada como modo de produção do conhecimento tendo a realidade e seu processo multifacetado como uma com-posição em que ancoramos de modo rizomático, com entradas e saídas plurais. Saídas estas que por não serem lineares nos deslocam e nos constituem docentes sempre num devir, num processo entre pares, numa ação afetiva e efetiva com estudantes e docentes.

Nosso entendimento é que a formação em exercício faz parte do desenvolvimento profissional docente e dessa formação decorre parte das práticas pedagógicas adotadas pelos/as docentes em sua atuação no contexto escolar. Haja vista que, conforme nos aponta Alves (2002), a formação precisa ser compreendida num contexto que sempre é plural e traz nesse bojo os desafios da profissão em suas múltiplas dimensões, a saber: o das propostas oficiais, os das práticas pedagógicas cotidianas, das culturas vividas e os das pesquisas em educação.

Encharcadas de experiências ancoradas no real e no dinamismo que constitui a docência e discência, assim como a formação e auto formação de professoras-pesquisadoras como processualidades, concluímos este texto com a certeza de que os registros advindos da potencialidade do uso dos diários de aula/pesquisa on-line será certamente ampliada, desdobrada, tensionada por leitores e leitoras que como coautoras e coautores ousam criar novos modos e dispositivos de pesquisa à guisa deleuziana.

Tessituras construídas como meados de linhas multicolor em que os nós e fios heterogêneos se entrelaçam e nos convoca à provisoriedade das verdades sempre em movimento. Portanto, em devir no campo da pesquisa em educação, cujo rigor comporta a produção de subjetividades, de afetos e de poesia, literaturizando a ciência que produzimos. 
Assim, defendemos a construção de uma ciência filógina, em que a cultura como produção social, enxergue as mulheres e suas produções autorais cujas narrativas insurgentes rasuram verdades cristalizadas. Neste texto, apresentamos o dispositivo que fecundou nossa ação de ensinar-pesquisar: os diários de aula/de pesquisa on-line. Outros virão!!!!

\section{REFERÊNCIAS}

ALVES, N. A experiência da diversidade no cotidiano e suas consequências na formação de professores. In: VICTORIO FILHO, A.; MONTEIRO, S. (org.). Cultura e conhecimento de professores. Rio de Janeiro: DP \&A, 2002. p. 13-30.

BARROS, L. P. de; KASTRUP, V. Cartografar é acompanhar processos. p. 52-75. In: PASSOS, E.; KASTRUP, V.; ESCÓSSIA L. da (org.). Pistas do método da cartografia: pesquisa-intervenção e produção de subjetividade. Porto Alegre: Sulina, 2015.

BARROS, R. B. de; PASSOS, E. A cartografia como método de pesquisa-intervenção. In: PASSOS, E.; KASTRUP, V.; ESCÓSSIA, L. da (org.). Pistas do método da cartografia: pesquisa-intervenção e produção de subjetividade. Porto Alegre: Sulina, 2015.

BARBIER, R. A pesquisa-ação. Tradução: L. Didio, Brasília: Liberlivro, 2007.

BUTLER, J. Relatar a si mesmo: crítica da violência ética. Betonni. 1 reimp. Belo Horizonte: Autêntica Editora, 2015.

DELEUZE, G.; GUATTARI, F. Mil platôs: capitalismo e esquizofrenia. Rio de Janeiro: 34,1995.

DELEUZE, G.; GUATTARI, F. Mil platôs: capitalismo e esquizofrenia 2. Tradução A. L. de Oliveira; A. G. Neto; C. P. Costa. V. 1. São Paulo: Editora 34, 2011.

KHOAN, Walter. Dossiê Gilles Deleuze. Educação e realidade. Porto Alegre, v. 27 n. 2 p. 123-130 jul./dez. 2002.

MARCUSCHI, L. A. O hipertexto como um novo espaço de escrita em sala de aula. Linguagem \& Ensino, v. 4, n. 1, 2001. p. 79-111.

MONTEIRO, A.; MENDES, J. R. Salas de aula como espaços de com-posições da diferença na formação docente. RECC - Revista de Educação, Ciência e Cultura, Canoas, v. 23, n. 1, p. 13-25, mar. 2018. Disponível em: http://revistas.unilasalle.edu.br/index.php/Educacao. Acesso em: 21 dez. 2019. 
NUNES, A. Cartografias de uma tese em/sobre deslocamentos territoriais. Encontro da Associação Nacional de Pesquisadores das Artes Plásticas -ANPAP 2015, 24. Simpósio 8 - Pesquisa em educação e metodologias artísticas: entre fronteiras, conexões e compartilhamentos. Anais [...], Santa Maria-RS, 22 a 26 set. 2015. Disponível em: http://anpap.org.br/anais/2015/simposios/s8/ aline_nunes.pdf. Acesso em: 30 dez. 2019.

PRADO FILHO, K.; TETI, M. M. A cartografia como método para as ciências humanas e sociais. Barbarói, Santa Cruz do Sul, n.38, p.45-59, jan./jun. 2013.

RIBEIRO, M. R. F.; BARBOSA, J. G. Diário de pesquisa e aprendizagem multirreferencial na cibercultura. In: SANTOS, E.; CAPUTO, S. G. Diário de pesquisa na cibercultura: narrativas multirreferenciais com os cotidianos. Rio de Janeiro-RJ: Omodê, 2018.

ROMAGNOLI, R. C. A cartografia e a relação pesquisa e vida. Psicologia \& Sociedade, v. 21, n. 2, p. 166-173, 2009.

SADE, C.; FERRAZ, G. C.; ROCHA, J. M. O ethos da confiança na pesquisa cartográfica: experiência compartilhada e aumento da potência de agir. p. 66-91. In: PASSOS, E.; KASTRUP, V.; ESCÓSSIA L. da (org.). Pistas do método da cartografia: pesquisa-intervenção e produção de subjetividade. Porto Alegre: Sulina, 2015.

SADE, C.; FERRAZ, G. C.; ROCHA, J. M. O ethos da confiança na pesquisa cartográfica: experiência compartilhada e aumento da potência de agir. Fractal: Revista de Psicologia, v. 25, n. 2, p. 281-298, 2013. Disponível em: http://periodicos.uff.br/fractal/article/view/4943/4785. Acesso em: 30 dez. 2019.

SANTOS, E.; WEBER, A. Diários online, cibercultura e pesquisa-formação multirreferencial. In: SANTOS, E.; CAPUTO, S. G. Diário de pesquisa na cibercultura: narrativas multirreferenciais com os cotidianos. Rio de Janeiro-RJ: Omodê, 2018.

SILVA, M. Educar na cibercultura: desafios à formação de professores para docência em cursos online. Revista Digital de tecnologias cognitivas, v. 3, n. 2010, p. 39-51, 2010. 
1 Pós-doutora em Educação - UFTM; Professora titular da Universidade do Estado da Bahia - UNEB; e líder do Grupo de Pesquisa DIFEBA; Pesquisadora do Grupo de Pesquisa Docência, Narrativa e Diversidade - DIVERSO.

E-mail: analucias12@gmail.com

2 Mestranda em Educação e Diversidade - UNEB; Membro do Grupo de Pesquisa - DIFEBA.

E-mail: laiabreu@gmail.com

3 Mestranda em Educação e Diversidade - UNEB; Membro do Grupo de Pesquisa - DIFEBA.

E-mail: vanessas.rita@hotmail.com

\section{(). (1) (-)}

Este artigo é licenciado na modalidade acesso abertosob a Atribuição-Compartilhalgual CC BY-SA

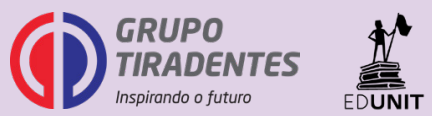

